Check for updates

Cite this: RSC Adv., 2019, 9, 32995

\title{
Sapitinib: reactive intermediates and bioactivation pathways characterized by LC-MS/MS $\uparrow$
}

\author{
Mohamed W. Attwa (iD *ab and Adnan A. Kadi ${ }^{\mathrm{a}}$
}

Sapitinib (AZD8931, SAP) is an epidermal growth factor receptor (EGFR) family (pan-erbB) tyrosine kinase inhibitor. In multiple tumor cell lines, SAP has been shown to be a much more potent inhibitor of EGFdriven cellular proliferation than gefitinib. In this in vitro metabolic study, we tested the generation of reactive intermediates from SAP using human liver microsomes and a capturing agent (potassium cyanide) to trap the iminium reactive intermediates. The same metabolic reaction was further repeated in the presence of methoxyamine to trap aldehyde intermediates. The identification of SAP metabolites revealed that the hydroxylation metabolic reaction represents the major in vitro metabolic pathway occurring at the piperidine moiety. We characterized six in vitro phase I metabolites in addition to three reactive intermediates (i.e., two iminiums and one aldehyde), therefore suggesting two probable SAPbioactivation pathways. We hypothesized that the piperidine ring nitrogen (cyclic tertiary amine) activated the two adjacent $\alpha$-carbons within the ring. The oxidative dealkylation of the $N$-acetamide group led to an unstable aldehyde that was trapped using methoxyamine, generating an oxime adduct that was detected using liquid chromatography-tandem mass spectrometry (LC-MS/MS). To the best of our knowledge, this is the first study presenting the structural characterization of SAP reactive intermediates.

Received 24th May 2019

Accepted 6th October 2019

DOI: 10.1039/c9ra03926k

rsc.li/rsc-advances formed during the initial stage of metabolism that can lead to various side effects. Because of the unstable nature of reactive species, capturing agents are usually used to generate stable adducts that can then be extracted, separated, and detected by liquid chromatography-tandem mass spectrometry (LC-MS/ MS). ${ }^{6-9}$

The systemic name of SAP is $2-[4-(\{4-[(3-$ chloro-2-fluorophenyl)amino]-7-methoxy-6-quinazolinyl\}oxy)-1-piper-

idinyl]- $N$-methylacetamide. Its chemical structure contains one piperidine ring linked to an $N$-methyl acetamide functional group (Fig. 1). During phase 1 metabolism, the $\alpha$-carbon adjacent to the tertiary nitrogen of the piperidine ring is hydroxylated, which leads to the loss of one water molecule, generating unstable and reactive iminium-ion species that can<smiles>CNC(=O)CN1CCC(Oc2cc3c(Nc4cccc(Cl)c4F)ncnc3cc2OC)CC1</smiles>

Sapitinib

Fig. 1 Chemical structure of Sapitinib.
${ }^{a}$ Department of Pharmaceutical Chemistry, College of Pharmacy, King Saud University, P. O. Box 2457, Riyadh, 11451, Saudi Arabia. E-mail: mzeidan@ksu.edu.sa; Fax: +966 114676 220; Tel: +966 114670237

${ }^{b}$ Students' University Hospital, Mansoura University, Mansoura 35516, Egypt

$\dagger$ Electronic supplementary information (ESI) available. See DOI: 10.1039/c9ra03926k 


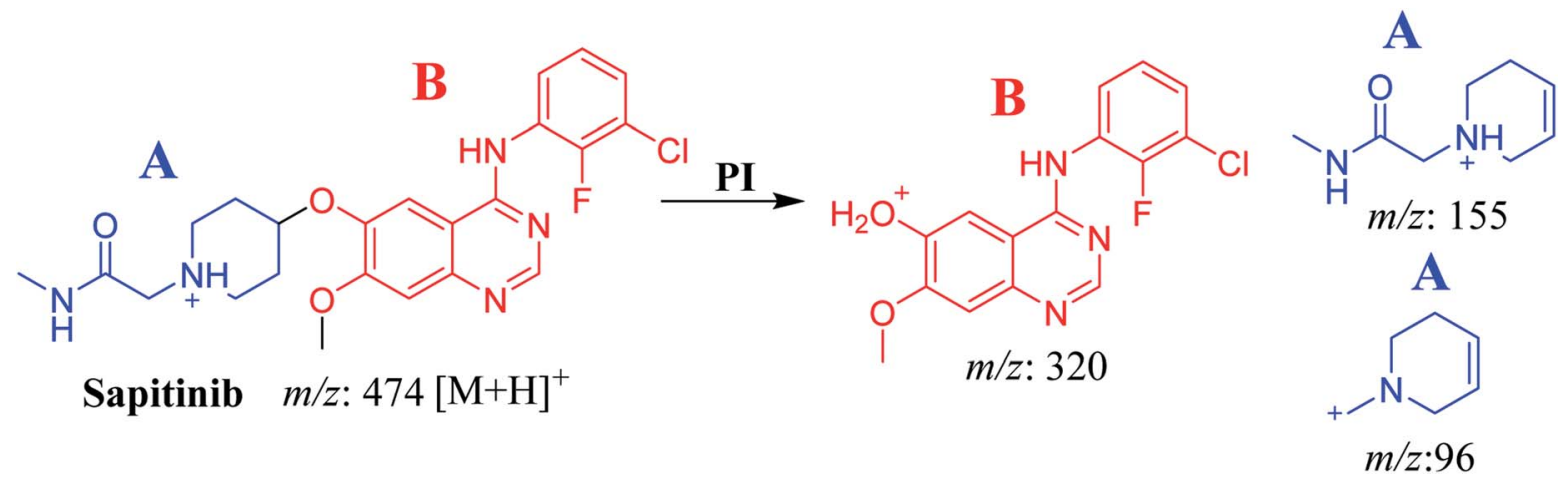

Scheme 1 Fragments (DIs) observed after fragmentation of SAP.

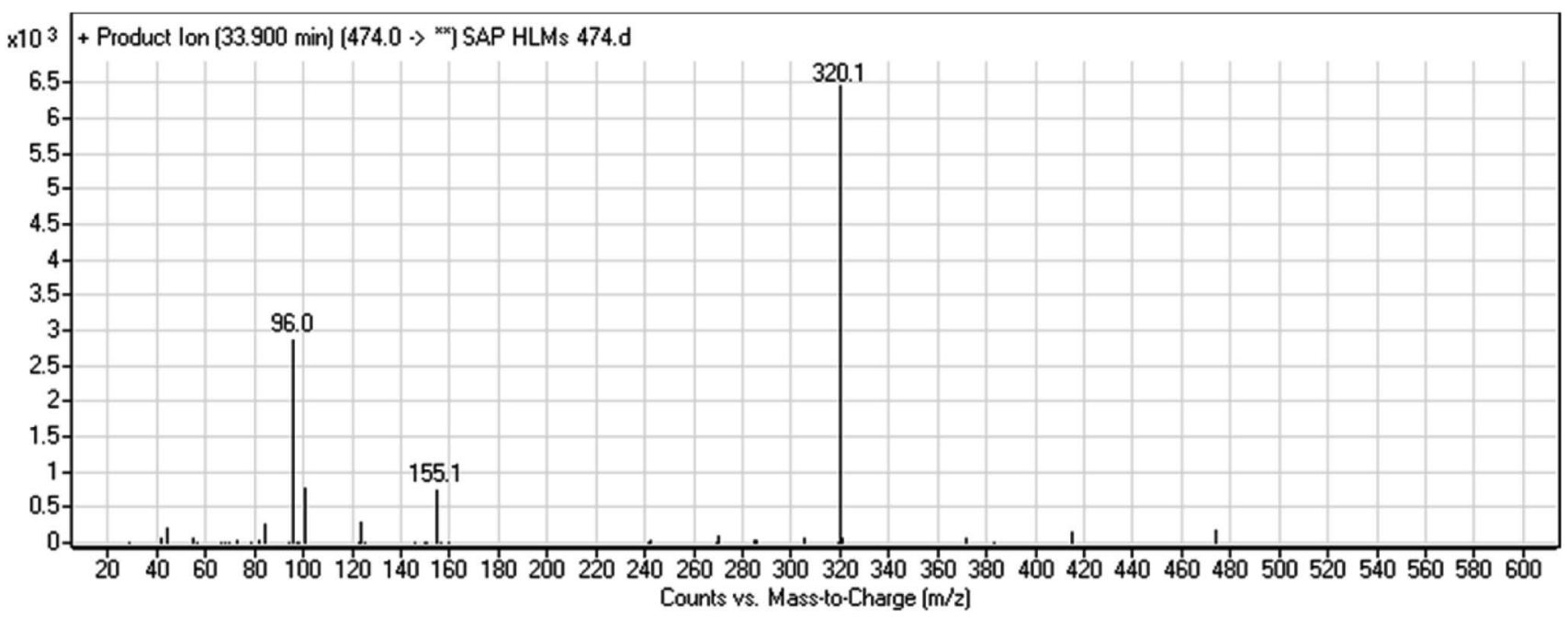

Fig. 2 SAP PI mass spectrum. SAP, sapitinib; PI, product ion.

be trapped using cyanide-forming stable adducts. The generation of iminium intermediates has been reported to be the main cause of drug-related toxicity. ${ }^{9-12}$ The $N$-methylacetamide group undergoes metabolism by oxidative dealkylation, generating aldehyde species that are unstable and can be captured using methoxyl amine to form an oxime adduct.

Table 1 In vitro reactive SAP metabolites

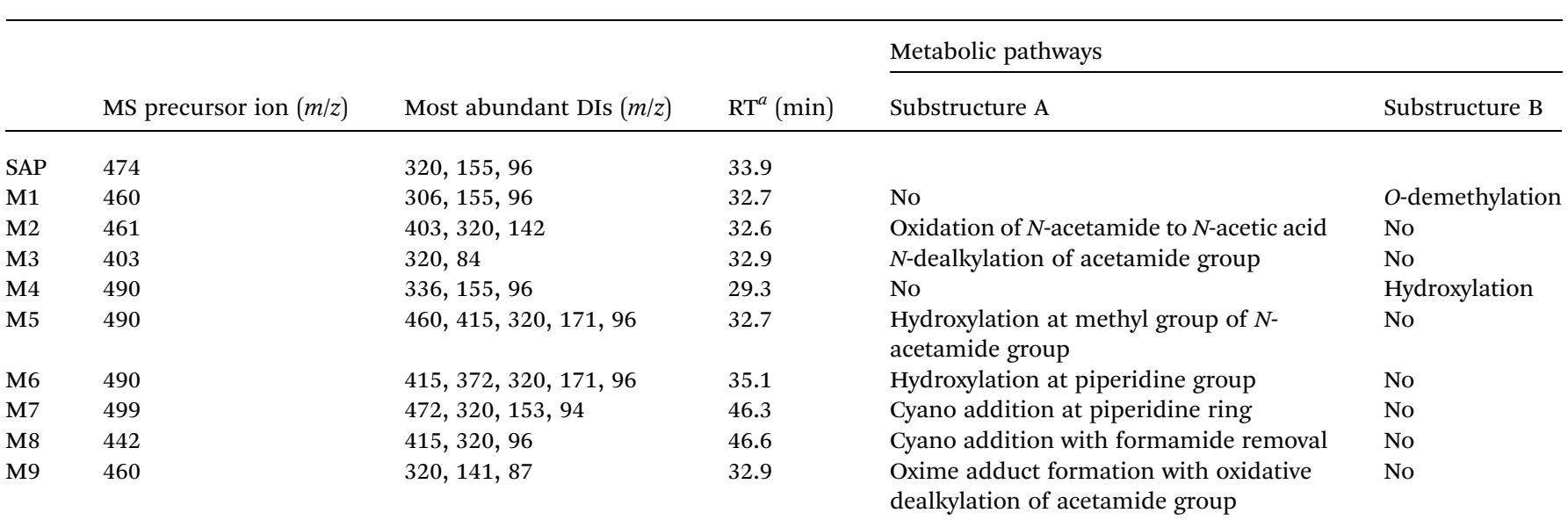

${ }^{a}$ RT, retention time; DI, daughter ion. 


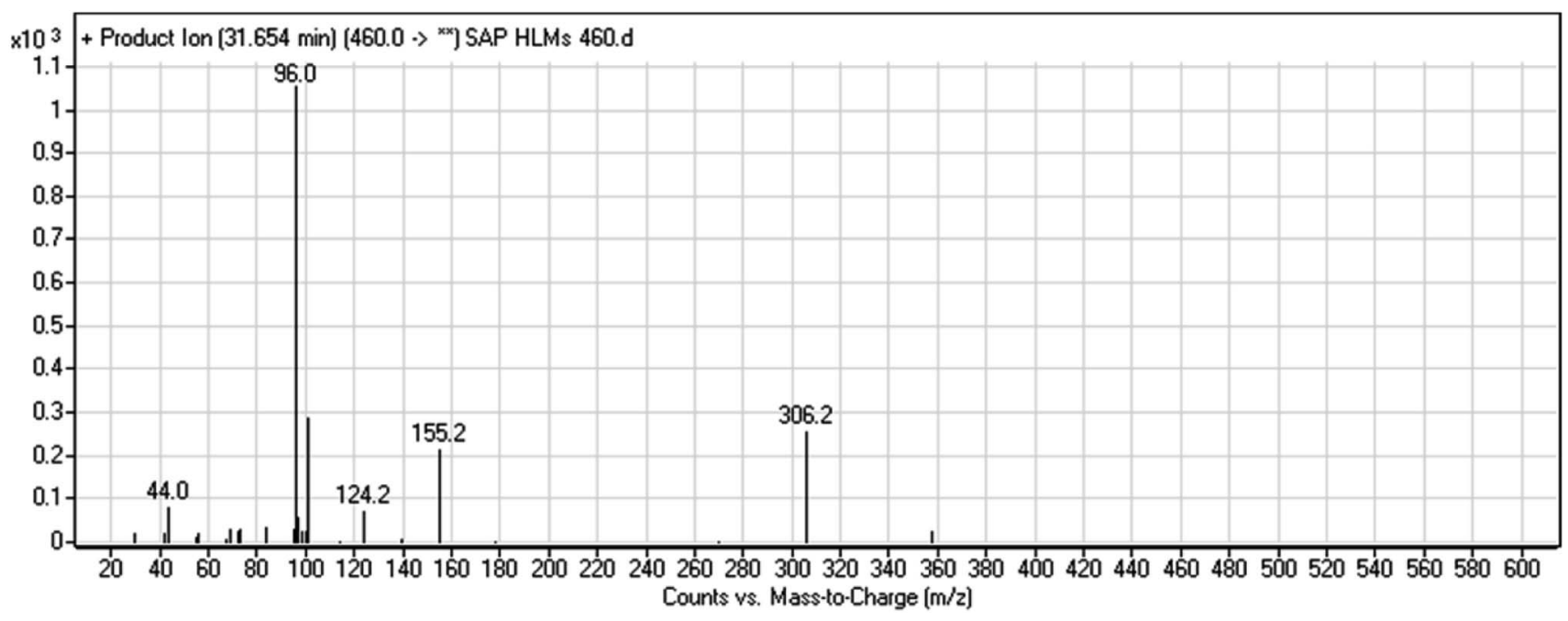

Fig. $3 \mathrm{M} 1 \mathrm{PI}$ mass spectrum.<smiles>CCC(CC[NH2+]CC(=O)NC)Oc1cc2c(Nc3cccc(Cl)c3F)ncnc2cc1O</smiles>
$m / z: 460$

Scheme 2 Fragments (DIs) observed after fragmentation of M1.

Aldehyde intermediates have been considered to be the cause of many side effects., ${ }^{9,13,14}$ These adducts can be characterized, separated, and identified using LC-MS/MS. ${ }^{6,7,15-18}$
The toxic adverse effects associated with SAP are therefore likely caused by the generation of reactive species. ${ }^{19}$ In this context, we investigated the phase I metabolism of SAP in human

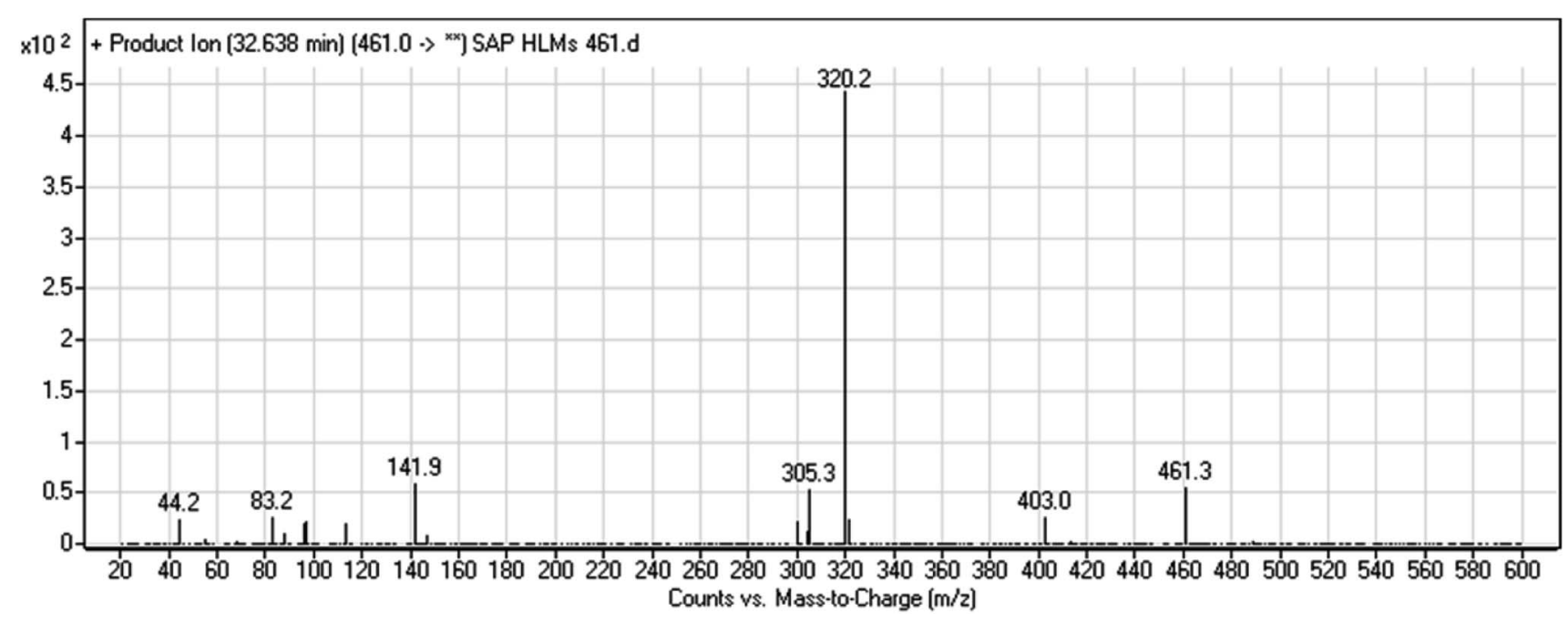

Fig. $4 \mathrm{M} 2 \mathrm{PI}$ mass spectrum. 
<smiles>COc1cc2ncnc(Nc3cccc(Cl)c3F)c2cc1OC1CC[NH2+]C(C)C1</smiles>

Scheme 3 Fragments (DIs) observed after fragmentation of M2.

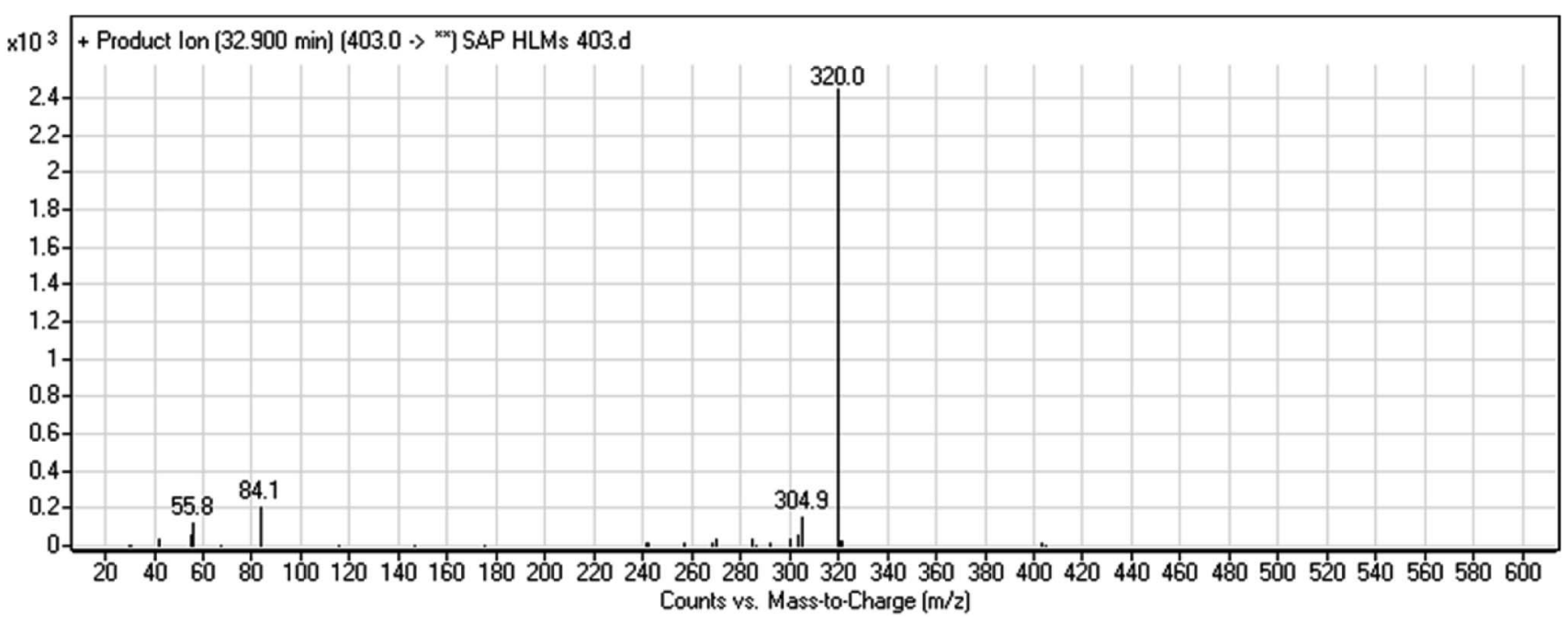

Fig. 5 M3 PI mass spectrum. SAP, sapitinib; PI, product ion.

liver microsomes (HLMs). We identified SAP-generated metabolites and reactive intermediates using LC-MS/MS in product ion scan mode, where compounds were fragmented in the collision cell and fragments detected in the third quadrupole. The qualitative daughter ions (DIs) corresponding to specific fragments of SAP were identified, enabling the characterization of SAP<smiles>COc1cc2ncnc(Nc3cccc(Cl)c3F)c2cc1OC1CC[NH2+]CC1</smiles><smiles>COc1cc2ncnc(Nc3cccc(Cl)c3F)c2cc1[OH2+]</smiles><smiles>C1=CC[NH2+]CC1</smiles>
$m / z: 403$

Scheme 4 Fragments (DIs) observed after fragmentation of M3. 


\section{A)}

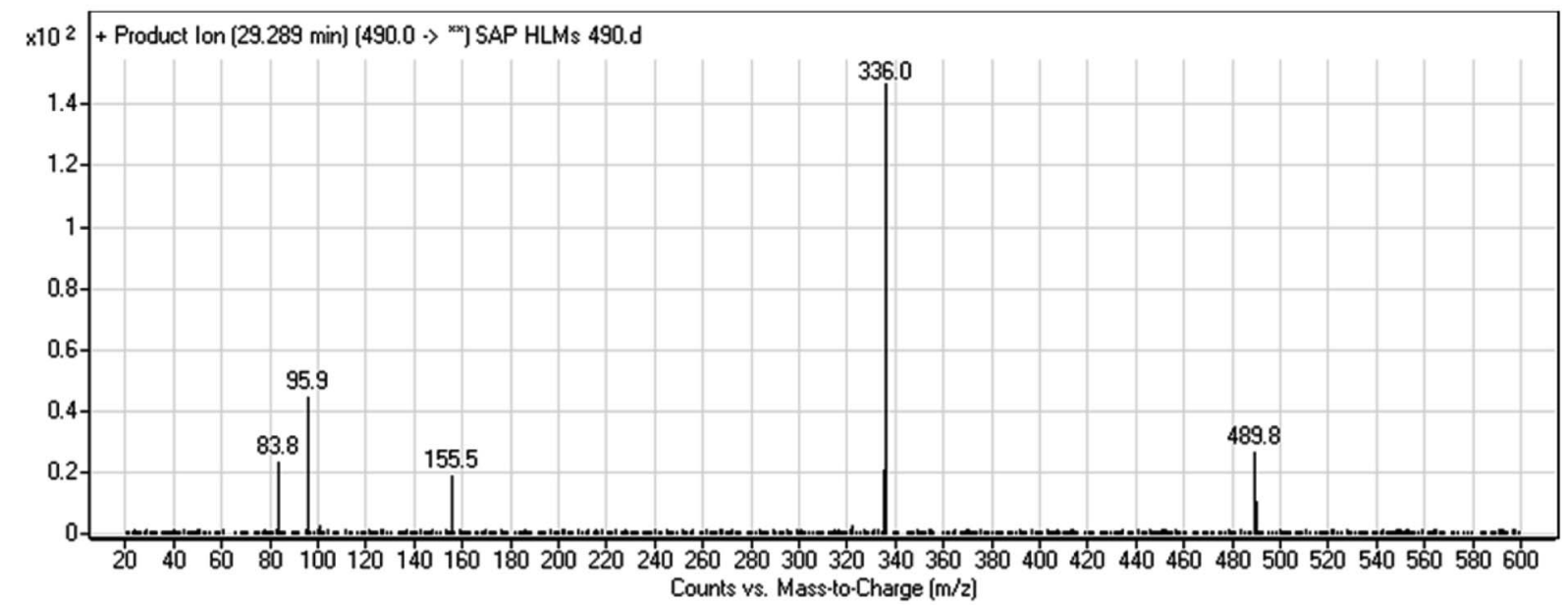

B)

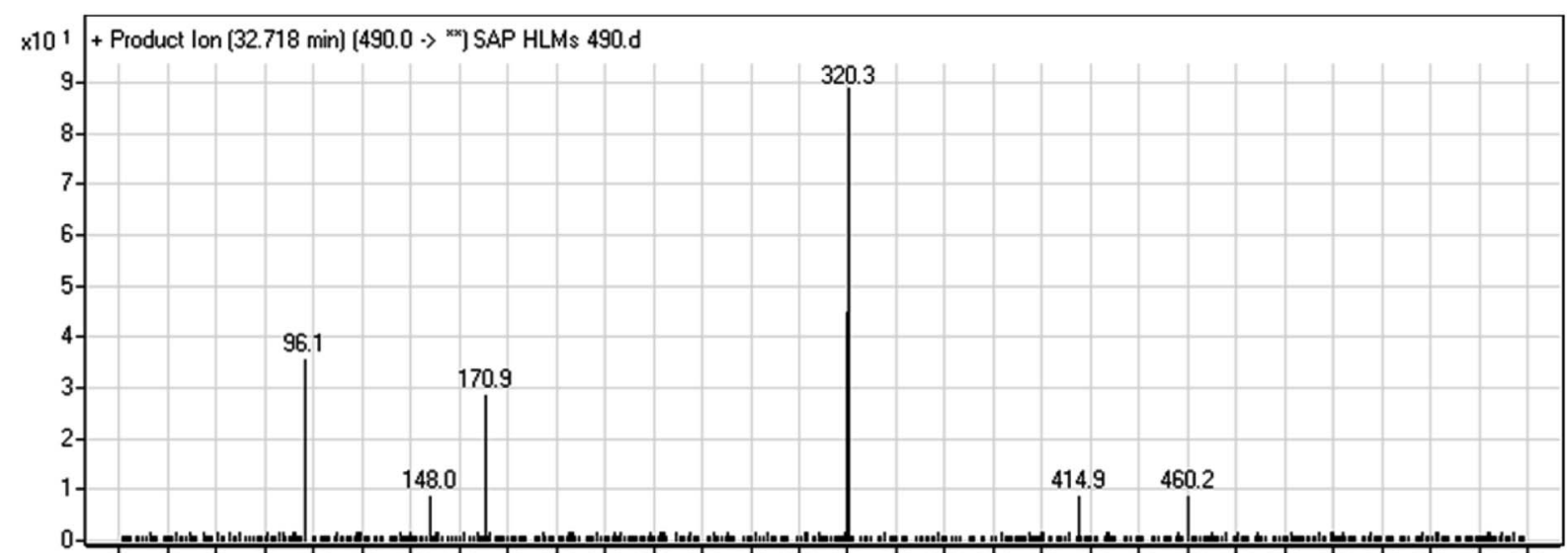

$20 \quad 4060 \quad 80100120140160180200220240260280300320340360380400420440460480500520540560580600$

C) Counts vs. Mass-to-Charge $(\mathrm{m} / \mathrm{z})$

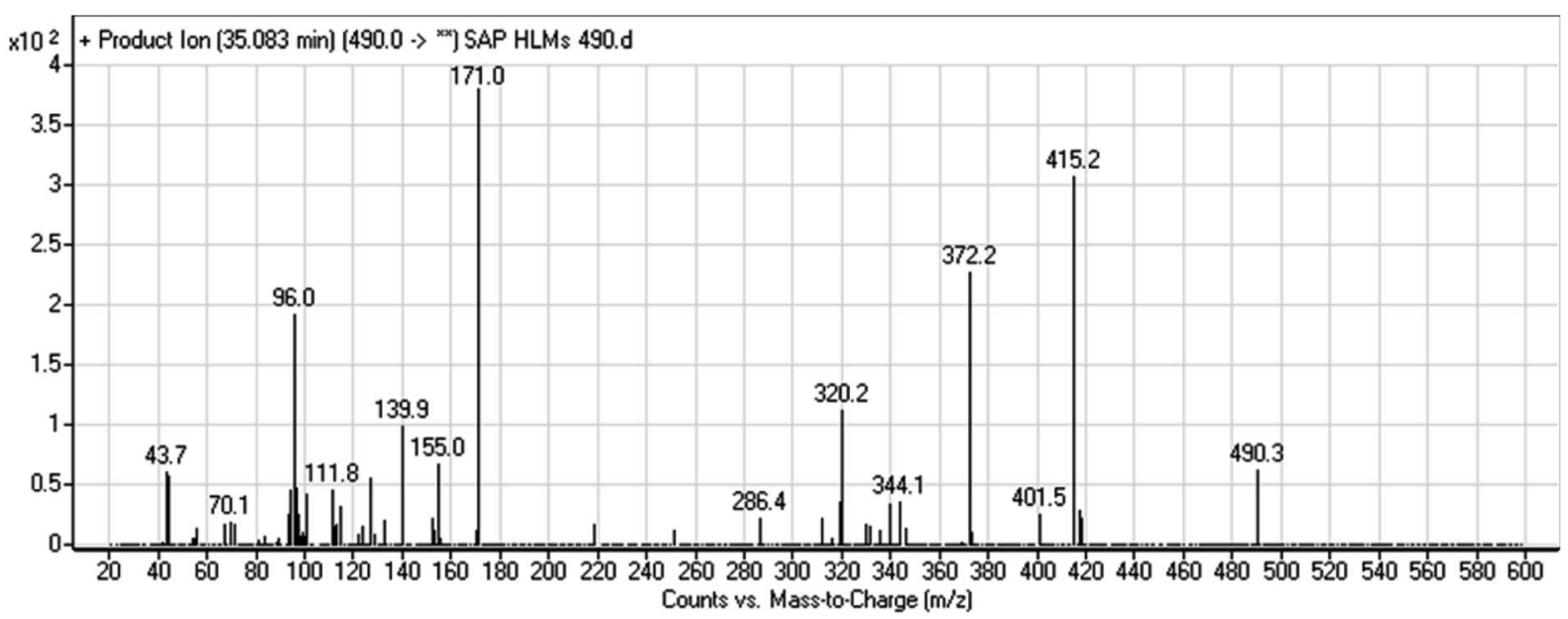

Fig. $6 \mathrm{PI}$ mass spectrum of M4 (A), M5 (B), and M6 (C). 


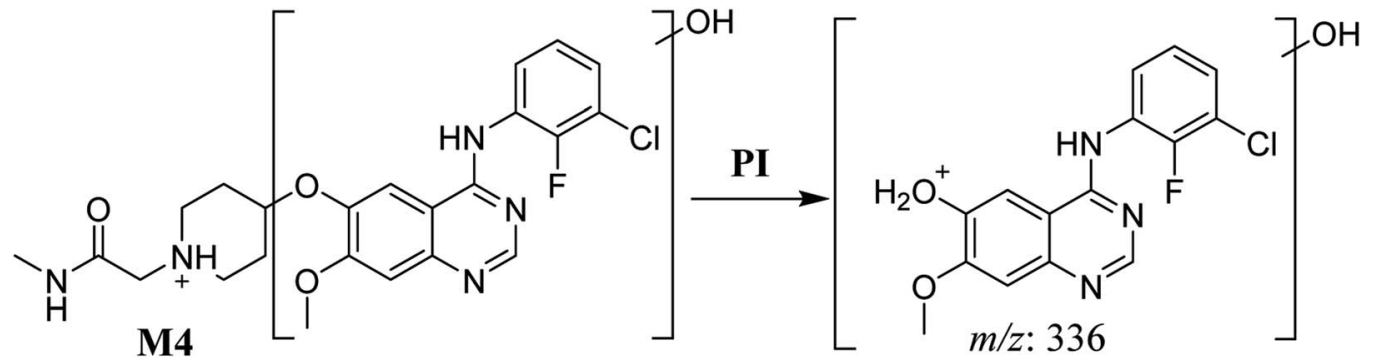
$m / z: 490$<smiles>CNC(=O)C[NH+]1CC=CCC1</smiles><smiles>[CH2+]N1CC=CCC1</smiles>

$m / z: 96$

Scheme 5 Fragments (DIs) observed after fragmentation of M4.

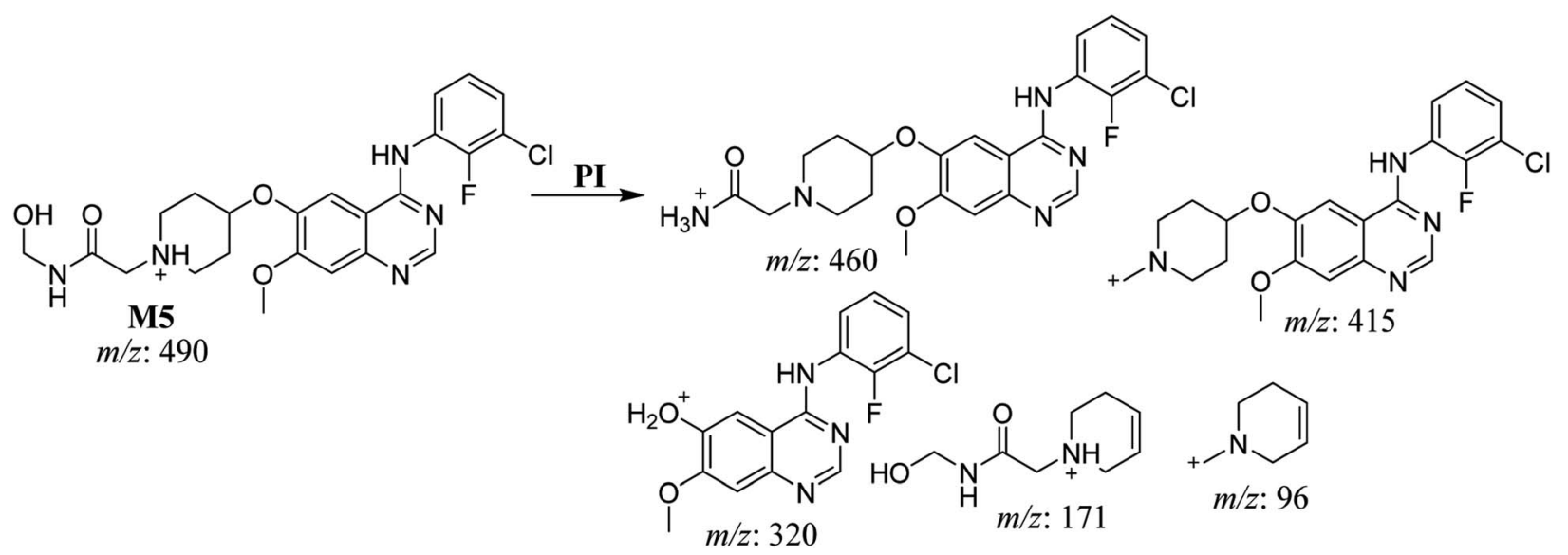

Scheme 6 Fragments (DIs) observed after fragmentation of M5.

metabolism and prediction of the chemical structures of the formed metabolites and reactive intermediates.

\section{Material and methods}

\subsection{Materials}

All solvents and chemicals were of analytical grade. HPLCgrade water $\left(\mathrm{H}_{2} \mathrm{O}\right)$ was generated by a Milli-Q plus filtration system (Millipore, Billerica, MA, USA). SAP was purchased from MedChem Express (NJ, USA). HPLC-grade acetonitrile (ACN), methoxyamine $\left(\mathrm{MeONH}_{2}\right)$, human liver microsomes (HLMs, M0567), ammonium formate $\left(\mathrm{NH}_{4^{-}}\right.$ $\mathrm{COOH})$, formic acid ( $\mathrm{HCOOH})$, and potassium cyanide (KCN) were purchased from Sigma-Aldrich (St. Louis, MO, USA).

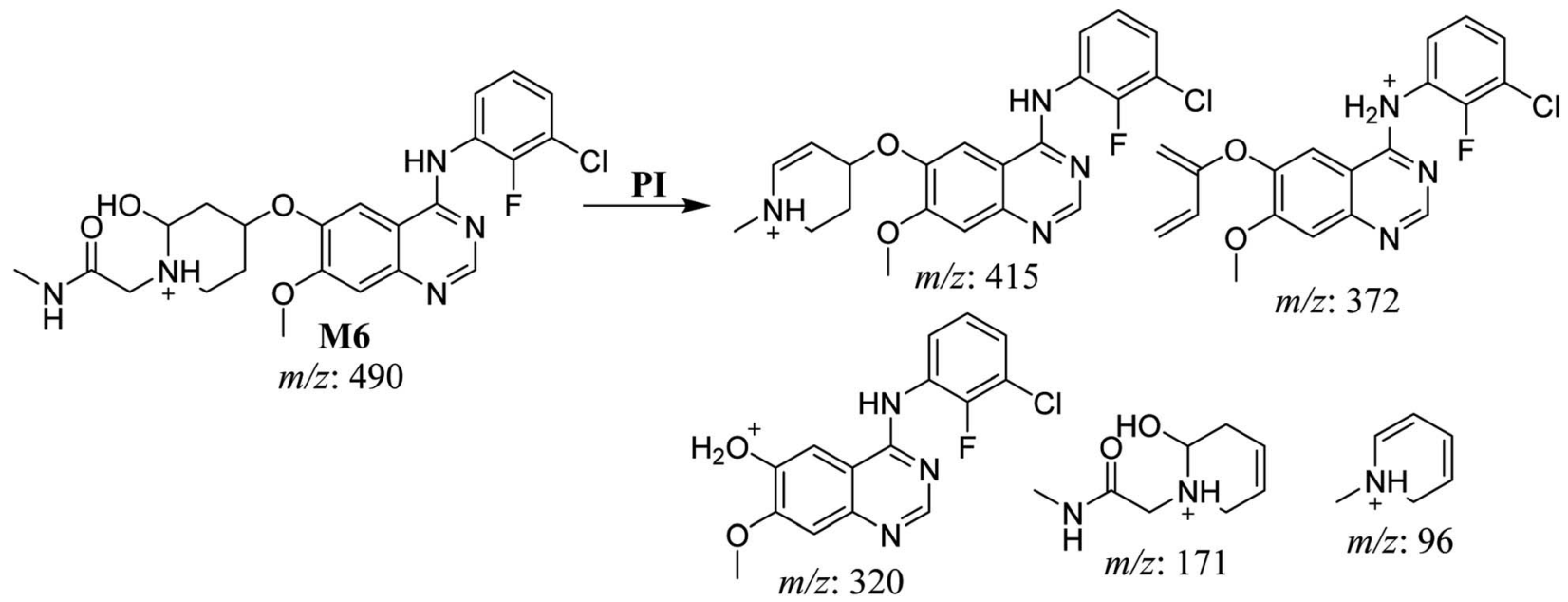

Scheme 7 Fragments (DIs) observed after fragmentation of M6. 


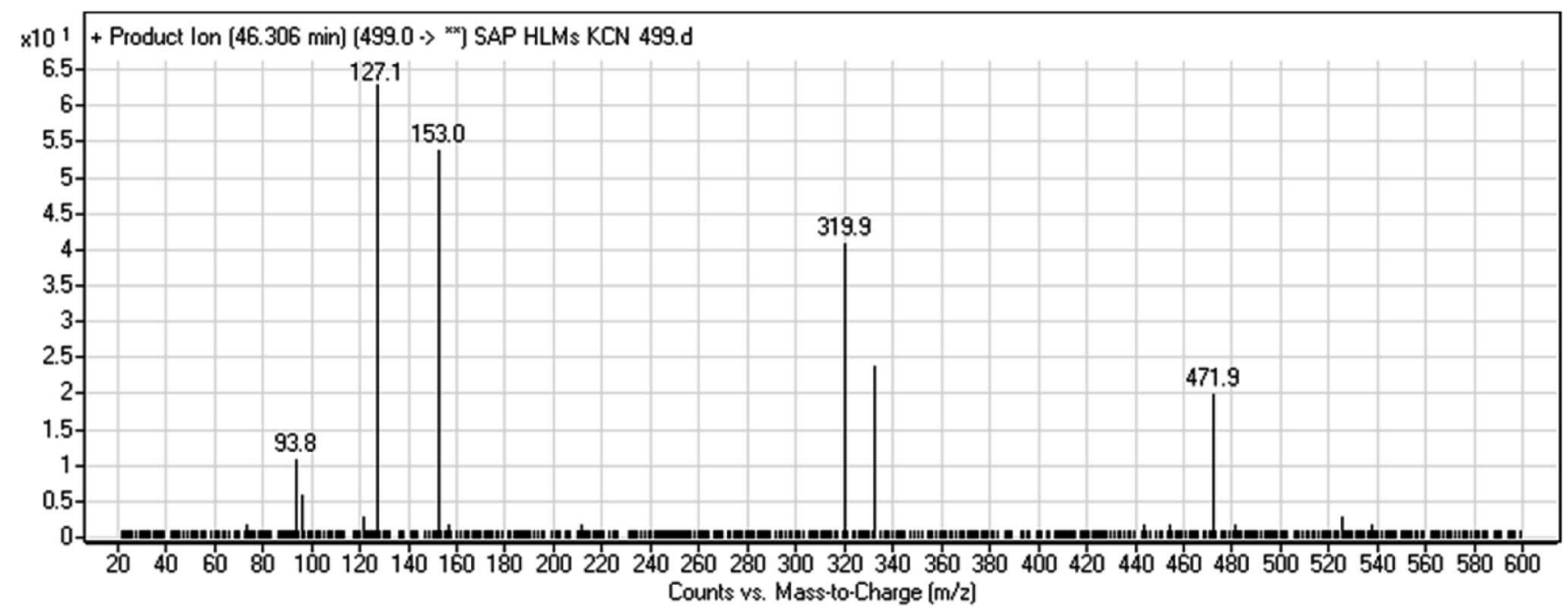

Fig. 7 M7 PI mass spectrum.

\subsection{Liquid chromatography-tandem mass spectrometry}

The chromatographic analysis of SAP HLM-incubation mixtures was carried out using an Agilent 1200 RRLC system (Agilent Technologies). For identification and characterization of SAP metabolites and its reactive intermediates (i.e., cyano and oxime adducts), the LC system was hyphenated to an Agilent 6410 Triple Quadrupole mass spectrometer (Agilent Technologies) equipped with an electrospray ionization (ESI) source. The separation was performed using a $\mathrm{C}_{18}$ stationary phase $(150 \mathrm{~mm}$ $\times 2.1 \mathrm{~mm}, 3.5 \mu \mathrm{m})$ thermostated at $20 \pm 2{ }^{\circ} \mathrm{C}$. The mobile phase was composed of $10 \mathrm{mM}$ ammonium formate at $\mathrm{pH} 4.2$ (solvent A) and ACN (solvent B). The flow rate was $0.25 \mathrm{~mL} \mathrm{~min}^{-1}$. The stepwise-gradient was the following: solvent $\mathrm{B}(5 \% ; 0-5 \mathrm{~min})$, solvent B (5-40\%; 5-40 min), solvent B (40-80\%; 40-60 min), and solvent B (80-5\%; 60-65 min). A post-run re-equilibration time of 15 min was used. The sample injection volume was 20 $\mu \mathrm{L}$. The MS experimental parameters were optimized for SAP, its metabolites, and the reactive metabolites using flow injection analysis. Fragmentation of SAP, metabolites, and trapped reactive metabolites were done in the collision cell of the triple quadrupole mass analyzer. Detection was done in ESI positive ion mode. ${ }^{18,19}$ ESI temperature, fragmentor voltage, and capillary tube voltage were set at $350{ }^{\circ} \mathrm{C}, 135 \mathrm{~V}$, and $4000 \mathrm{~V}$, respectively. The collision energy was fixed at $25 \mathrm{eV}$ for all compounds. Nitrogen (low-purity) was utilized as drying gas at a flow rate of $12 \mathrm{~L} \mathrm{~min}^{-1}$. Nitrogen (high-purity) was used as collision gas at a pressure of $55 \mathrm{psi}$. Data acquisition and instrument management was carried out using Mass Hunter software (Agilent Technologies).

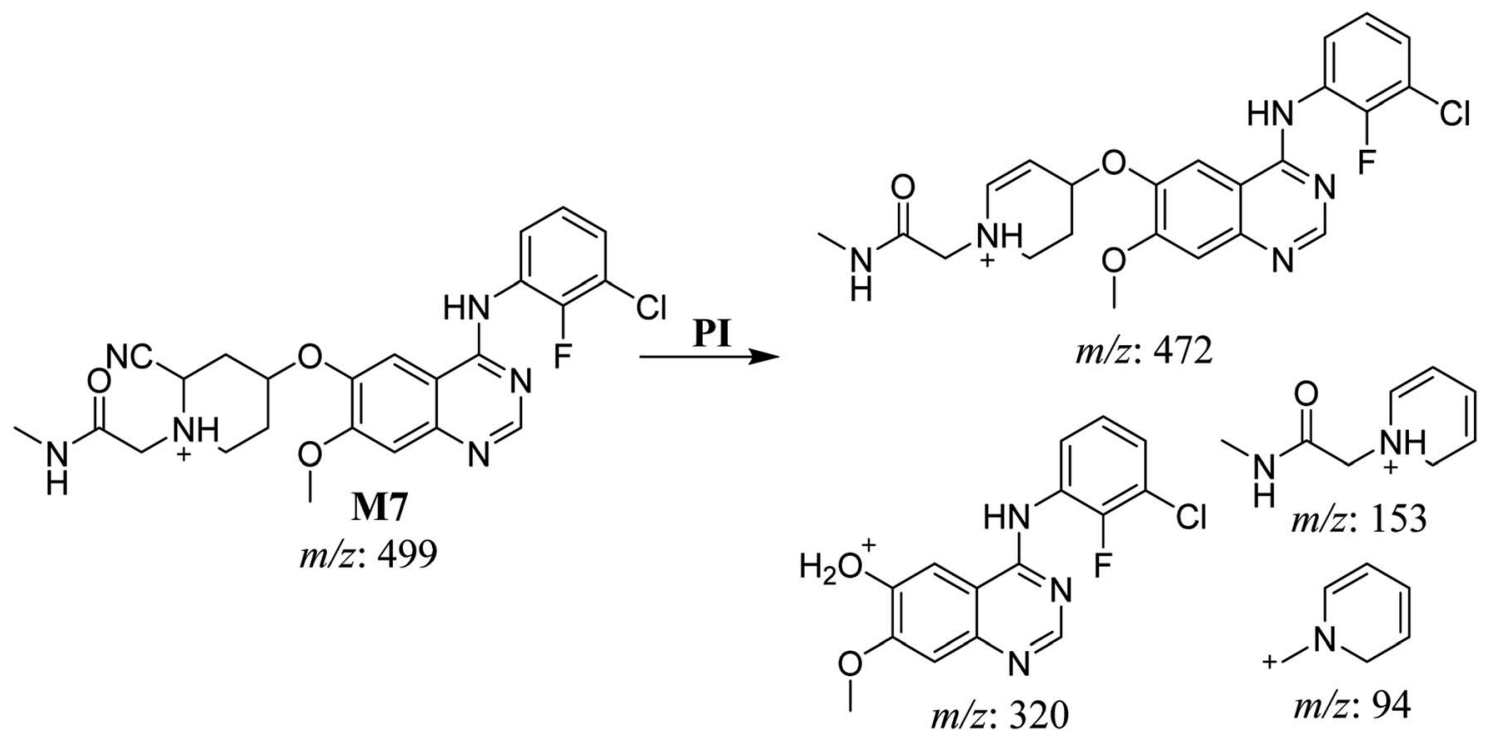

Scheme 8 Fragments (DIs) observed after fragmentation of M7. 


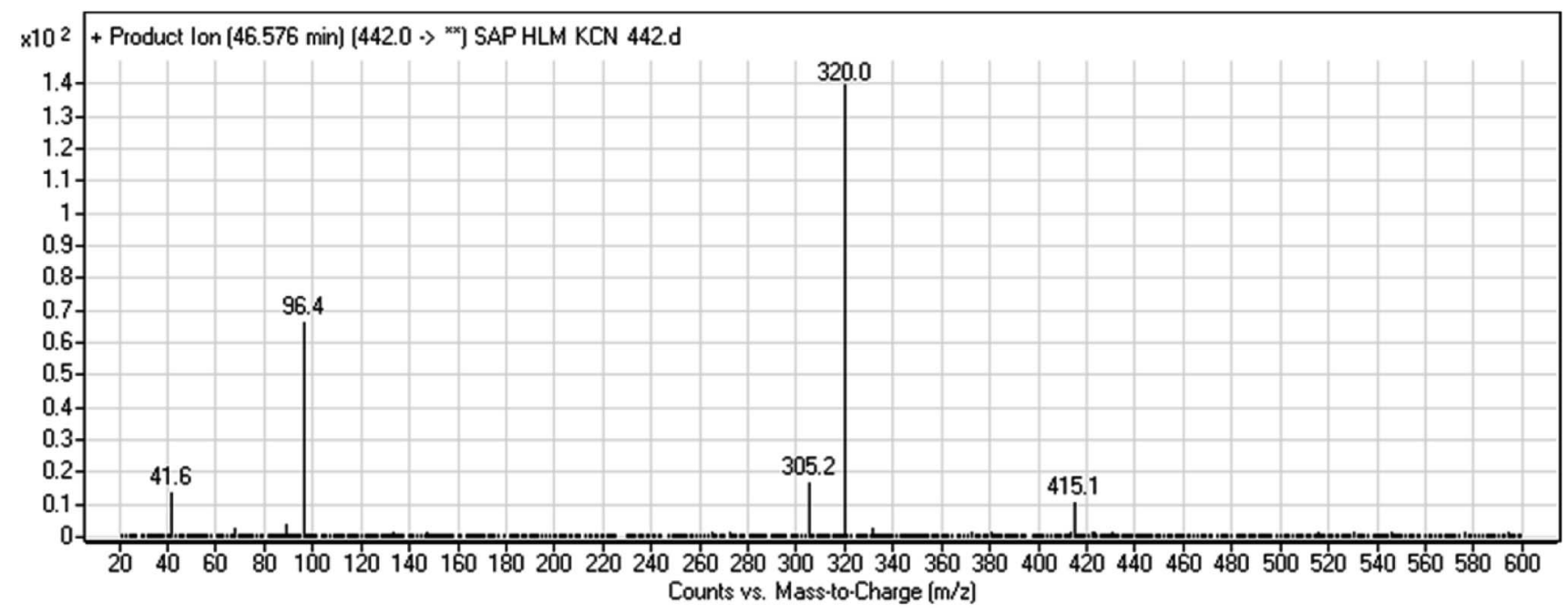

Fig. $8 \mathrm{M} 8 \mathrm{PI}$ mass spectrum.

\subsection{SAP metabolism in HLMs}

SAP (10 $\mu \mathrm{M}$ in DMSO) was incubated with HLMs $\left(1.0 \mathrm{mg} \mathrm{mL}{ }^{-1}\right)$ for $2 \mathrm{~h}$ in an incubation mixture of $\mathrm{Na} / \mathrm{K}$ phosphate buffer (50 mM, pH 7.4) and magnesium chloride (3.3 mM) in a shaking water bath $\left(37^{\circ} \mathrm{C}\right)$. The metabolism was initiated by adding a solution of $1.0 \mathrm{mM} \mathrm{NADPH}$ and quenched with addition of $2 \mathrm{~mL}$ ice-cold ACN leading to protein precipitation. After centrifugation at $9000 \times g$ for $10 \mathrm{~min}$ at $4{ }^{\circ} \mathrm{C}$, the supernatant was collected and evaporated under a gentle stream of nitrogen. The residue was then reconstituted in the mobile phase and transferred into HPLC vials prior to LC-MS/MS analysis. ${ }^{\mathbf{2 0 - 2 3}}$

\subsection{Generation of reactive intermediates}

SAP was incubated in HLMs using KCN (1.0 mM) or $\mathrm{MeONH}_{2}$ $(2.5 \mathrm{mM})$ as trapping agents for iminium species or aldehyde intermediates, respectively. The trapping agents were added before the initiation of metabolism (NADPH addition). Experiments were repeated three independent times for method validation.

\subsection{Identification of SAP reactive metabolites}

Characterization of SAP and its related metabolites in the incubation mixture was done using extracted ion chromatograms of the daughter ions' (DIs) chromatographic peaks. Among those, DIs representing a substructure of the parent metabolite were considered. These fragments enabled the prediction of the compound sites exposed to phase I metabolism as well as the chemical structures of the formed SAP metabolites.

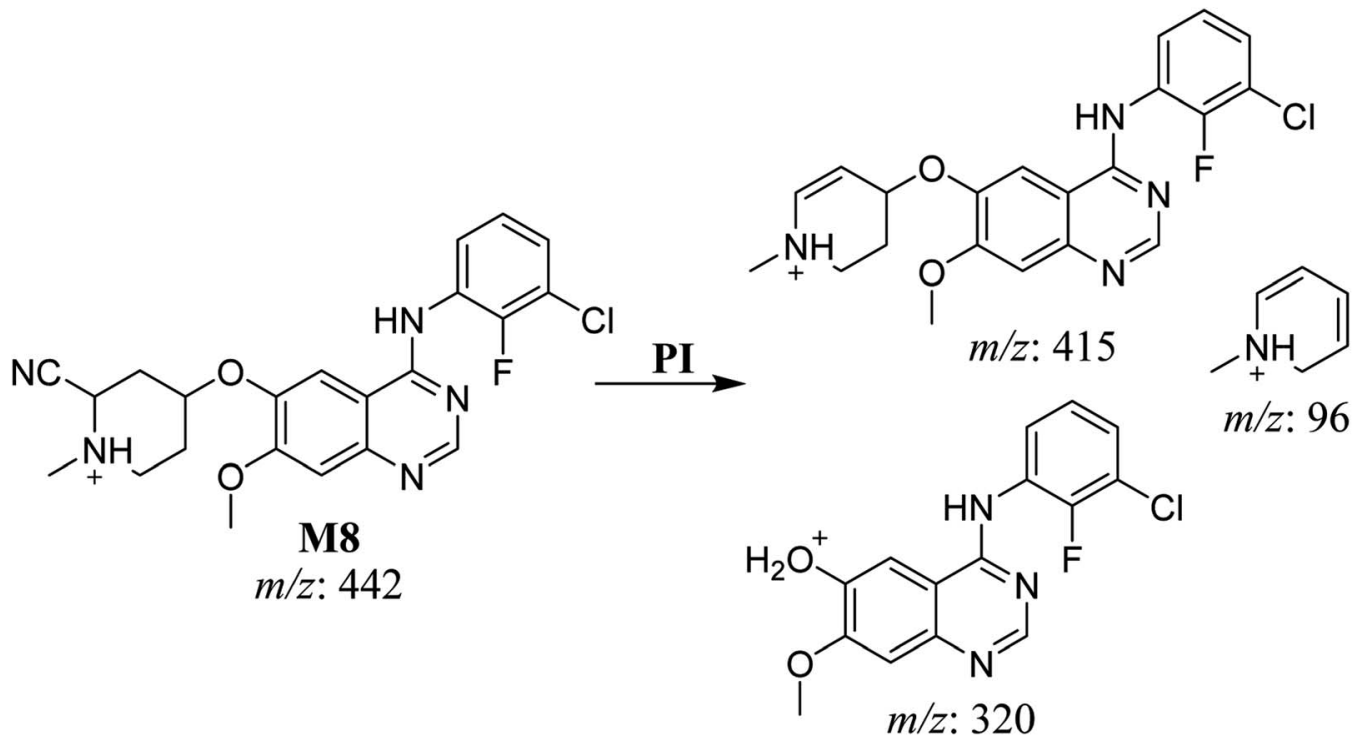

Scheme 9 Fragments (DIs) observed after fragmentation of M8. 


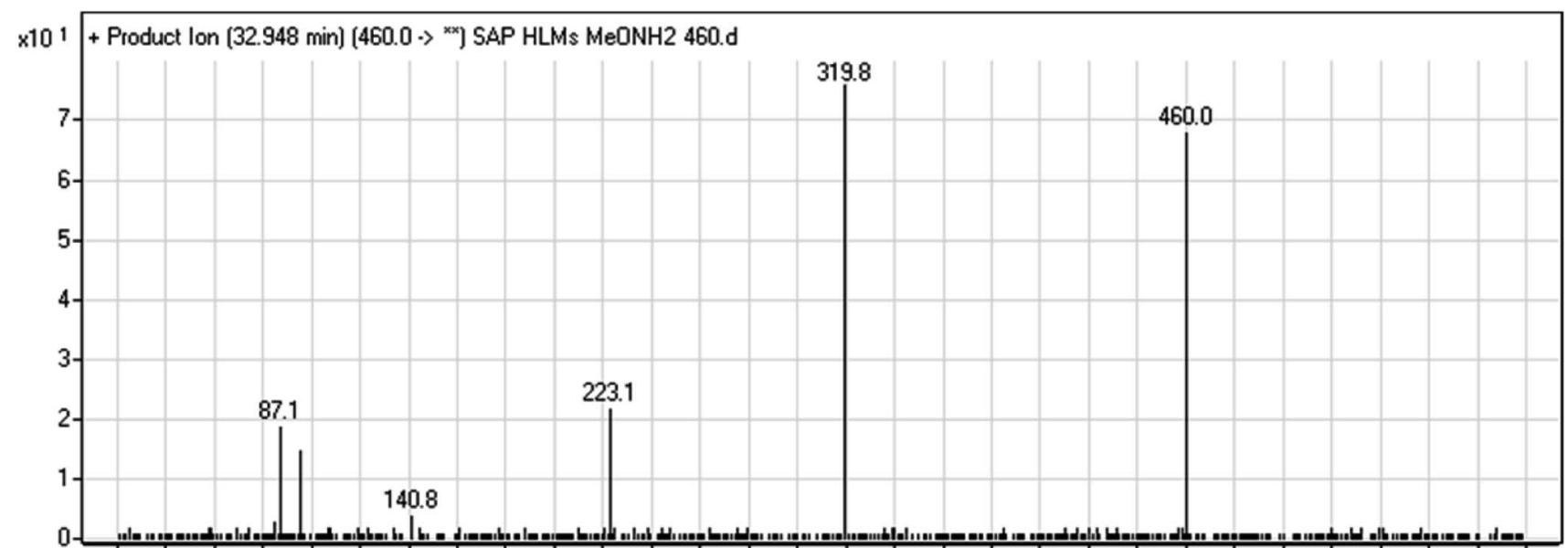

$2040 \quad 6080100120140160180200220240260280300320340 \quad 360380400420440460480500520540560580600$ Counts vs. Mass-to-Charge $[\mathrm{m} / \mathrm{z}]$

Fig. $9 \mathrm{M9}$ PI mass spectrum

\section{Results and discussion}

\subsection{SAP fragmentation pattern}

The chemical structure of SAP is shown as two substructures, i.e., A (blue) and B (red) (Scheme 1), to facilitate the identification of metabolic pathways characterized by changes in relevant DIs. SAP chromatographic peak was detected at $33.9 \mathrm{~min}$. Fragmentation of the SAP ion detected at $\mathrm{m} / \mathrm{z} 474$ (corresponding to the $[\mathrm{M}+\mathrm{H}]^{+}$form) resulted in three qualitative DIs detected at $m / z 320, m / z \quad 155$, and $m / z 96$ (Fig. 2). These DIs showed a relevant substructure that enabled the determination of phase I metabolism pathways in HLMs and prediction of related SAP metabolites structures (Scheme 1).

\subsection{Identification of SAP-related metabolites}

We identified hydroxylation reaction as being the major pathway in in vitro SAP metabolism. Indeed, two cyano and one oxime adducts were identified after metabolic incubation with HLMs in the presence of $1.0 \mathrm{mM} \mathrm{KCN}$ or $2.5 \mathrm{mM} \mathrm{MeONH}$, respectively (Table 1 ).

3.2.1. HLMs metabolite detected at $m / z 460$ (M1). The SAP metabolite detected at $\mathrm{m} / z 460$ (M1) eluted at $31.7 \mathrm{~min}$. The fragmentation of M1 ion at $m / z 460$ (corresponding to the [M + $\mathrm{H}]^{+}$form) resulted in three DIs detected at $\mathrm{m} / \mathrm{z} 306, \mathrm{~m} / \mathrm{z} 155$, and $m / z 96$ (Fig. 3). Compared with the fragmentation of SAP, the two DIs detected at $\mathrm{m} / \mathrm{z} 155$ and $\mathrm{m} / \mathrm{z} 96$ did not show any relevant metabolic pathway in the A substructure, whereas the DI detected at $\mathrm{m} / \mathrm{z} 306$ exhibited a loss of $14 \mathrm{Da}$, indicating an $O$ demethylation which is the only possible metabolic reaction in the B substructure (Scheme 2).

3.2.2. HLMs metabolite detected at $m / z 461$ (M2). The SAP metabolite detected at $\mathrm{m} / \mathrm{z} 461$ (M2) eluted at $32.6 \mathrm{~min}$. The fragmentation of $\mathrm{M} 2$ ion at $m / z 461$ (corresponding to the [M + $\mathrm{H}]^{+}$form) resulted in three DIs detected at $\mathrm{m} / \mathrm{z} 403, \mathrm{~m} / \mathrm{z} 320$, and $m / z 142$ (Fig. 4). Compared with SAP fragmentation, the DI detected at $\mathrm{m} / \mathrm{z} 320 \mathrm{did}$ not any relevant metabolic pathway in the B substructure, whereas the DI detected at $m / z 141$ indicated an oxidation of the $\mathrm{N}$-acetamide group to form $\mathrm{N}$-acetic acid, matching with the structure of the DI detected at $\mathrm{m} / \mathrm{z} 403$ (Scheme 3).

3.2.3. HLMs metabolite detected at $m / z 403$ (M3). The SAP metabolite detected at $\mathrm{m} / \mathrm{z} 403$ (M3) eluted at $32.9 \mathrm{~min}$. The fragmentation of M3 ion at $m / z 403$ (corresponding to the [M + $\mathrm{H}]^{+}$form) resulted in two qualitative DIs detected at $\mathrm{m} / \mathrm{z} 320$ and<smiles>CCC(CC[NH2+]/C=N/OC)Oc1cc2c(Nc3cccc(Cl)c3F)ncnc2cc1OC</smiles>

$m / z: 460$<smiles>COc1cc2ncnc(Nc3cccc(Cl)c3F)c2cc1[OH2+]</smiles>

$m / z: 320$<smiles>CO/N=C/NC1CC=CCC1</smiles>

$m / z: 141$<smiles>C=N/C=N/OC</smiles>

$m / z: 87$

Scheme 10 Fragments (DIs) observed after fragmentation of M9. 
$m / z 84$ (Fig. 5). Compared with SAP fragmentation, the DI detected at $m / z 320$ did not show any relevant metabolic pathway in the B substructure, whereas the DI detected at $m / z 84$ revealed $N$-dealkylation of the acetamide group (Scheme 4).

3.2.4. HLMs metabolites detected at $m / z 490$ (M4, M5, and M6). Many oxidized SAP metabolites were detected at $\mathrm{m} / \mathrm{z} 490$ (corresponding to the $[\mathrm{M}+\mathrm{H}]^{+}$form) with different elution times, with major peaks detected at $29.3 \mathrm{~min}, 32.7 \mathrm{~min}$, and $35.1 \mathrm{~min}$. The fragmentation of the ions detected at $\mathrm{m} / \mathrm{z} 490$ resulted in various DIs (Fig. 6A-C), suggesting that hydroxylation happened at multiple sites on the SAP molecule.

The fragmentation of the first ion detected at $m / z 490$ (corresponding to the $[\mathrm{M}+\mathrm{H}]^{+}$form), with a retention time of $29.3 \mathrm{~min}(\mathrm{M} 4)$, resulted in three DIs detected at $\mathrm{m} / \mathrm{z} 336, \mathrm{~m} / \mathrm{z}$
155, and $\mathrm{m} / \mathrm{z} 96$ (Fig. 6A). Compared with SAP fragmentation, the DIs detected at $m / z 155$ and $m / z 96$ did not show relevant metabolic pathway in the A substructure, whereas the DI detected at $\mathrm{m} / \mathrm{z} 336$ exhibited a loss of 16 Da that pointed out a hydroxylation in the B substructure (Scheme 5).

The fragmentation of the second ion detected at $\mathrm{m} / \mathrm{z} 490$ (corresponding to the $[\mathrm{M}+\mathrm{H}]^{+}$form), with a retention time of $32.7 \mathrm{~min}$ (M5) resulted in five DIs detected at $\mathrm{m} / \mathrm{z} 460, \mathrm{~m} / \mathrm{z} 415$, $m / z$ 320, $m / z$ 171, and $m / z 96$ (Fig. 6B). Compared with SAP fragmentation, the DIs detected at $\mathrm{m} / \mathrm{z} 320$ did not show any relevant metabolic pathway in the $\mathrm{B}$ substructure, whereas the DI detected at $m / z 171$ exhibited an addition of 16 Da that revealed an hydroxylation in the A substructure, which matched with the structure of the DI detected at $\mathrm{m} / \mathrm{z} 415$. The DI detected<smiles>CNC(=O)CN1CCC(Oc2cc3c(Nc4cccc(Cl)c4F)ncnc3cc2OCC#N)CC1</smiles><smiles>[R]C1CC[N+](C)(CC(=O)NC)CC1</smiles>

Iminium ion intermediates<smiles>[R]C1CC([Y19])N(CC(=O)NC)C(C#N)C1</smiles>

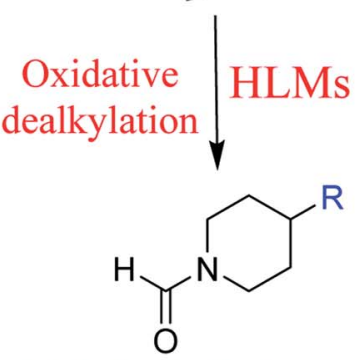

Aldehyde intermediate $\mathbf{M e O N H}_{2} \downarrow$ HLMs<smiles>[R]C1CCN(/C=N/OC)CC1</smiles>

Oxime adduct

\section{Cyano adducts}

Scheme 11 Suggested metabolism for the generation of iminium and aldehyde intermediates of SAP. 
at $m / z \quad 460$ showed a hydroxyl methyl loss that revealed a hydroxylation in the methyl group (Scheme 6).

The fragmentation of the third ion detected at $\mathrm{m} / \mathrm{z} 490$ (corresponding to the $[\mathrm{M}+\mathrm{H}]^{+}$form), with a retention time of $35.1 \mathrm{~min}(\mathrm{M} 6)$, resulted in five DIs detected at $\mathrm{m} / \mathrm{z} 415, \mathrm{~m} / \mathrm{z} 372$, $\mathrm{m} / \mathrm{z} 320, \mathrm{~m} / \mathrm{z} 171$, and $\mathrm{m} / \mathrm{z} 96$ (Fig. 6C). Compared with the SAP fragmentation, the DIs detected at $\mathrm{m} / z 320$ did not show any relevant metabolic pathway in the B substructure, whereas the DI detected at $m / z 171$ exhibited an addition of $16 \mathrm{Da}$ that revealed an hydroxylation in the A substructure, which matched with the structure of the DI detected at $\mathrm{m} / \mathrm{z}$ at 415 . The DI detected at $m / z 372$ showed a Retro-Diels-Alder reaction, indicating a hydroxylation of the piperidine group, which matched with the structure of the DI detected at $\mathrm{m} / \mathrm{z}$ at 96 (Scheme 7).

3.2.5. HLMs reactive metabolite detected at $m / z 499$ (M7). The metabolic bioactivation of SAP created an electron-deficient center on the molecule, which was attacked by a cyanonucleophile (electron-rich), generating reactive iminium species. The presence of DI showing a neutral loss of $27 \mathrm{Da}$, corresponding to a hydrogen cyanide unit, was used to detect potential cyano adducts as this fragment is characteristic for cyano adducts. ${ }^{10,12}$ During bioactivation of similar cyclic tertiary amine-containing drugs, ${ }^{24,25}$ the piperidine-ring carbons are supposed to be the bioactive center.

A cyano adduct of SAP metabolite detected at $m / z 499$ (corresponding to the $[\mathrm{M}+\mathrm{H}]^{+}$form) eluted at $46.3 \mathrm{~min}(\mathrm{M} 7)$. The fragmentation of $\mathrm{M} 7$ ion resulted in four DIs detected at $\mathrm{m} / \mathrm{z}$ $472, \mathrm{~m} / \mathrm{z} 320, \mathrm{~m} / \mathrm{z} 153$, and $\mathrm{m} / \mathrm{z} 94$ (Fig. 7). The DI detected at $\mathrm{m} / \mathrm{z}$ 472 showed a neutral loss of a hydrogen cyanide unit that confirmed the addition of a cyano moiety. Compared with SAP fragmentation, the DIs detected at $\mathrm{m} / \mathrm{z} 320$ did not show any relevant metabolic pathway in the B substructure, whereas the DI detected at $m / z 153$ showed and HCN loss, indicating cyano addition at the piperidine group in the A substructure, matching with the structure of the DI detected at $\mathrm{m} / \mathrm{z} 94$ (Scheme 8).
3.2.6. HLMs reactive metabolite detected at $m / z 442$ (M8). The cyano adduct of SAP metabolite detected at $\mathrm{m} / \mathrm{z} 442$ (corresponding to the $[\mathrm{M}+\mathrm{H}]^{+}$form) eluted at $46.5 \mathrm{~min}$ (M8). The fragmentation of M8 ion resulted in three DIs detected at $\mathrm{m} / \mathrm{z}$ $415, \mathrm{~m} / \mathrm{z} 320$, and $\mathrm{m} / \mathrm{z} 96$ (Fig. 8). The DI detected at $\mathrm{m} / \mathrm{z} 415$ showed a neutral loss of a hydrogen cyanide unit that confirmed the addition of a cyano moiety. Compared with SAP fragmentation, the DI detected at $\mathrm{m} / \mathrm{z} 320$ did not show and relevant metabolic pathway in the B substructure, whereas the DI detected at $\mathrm{m} / \mathrm{z} 415$ showed a loss of $27 \mathrm{Da}$, indicating the loss of an HCN unit characteristic of cyano addition at the piperidine group in the A substructure, matching with the structure of the DI detected at $m / z 96$ (Scheme 9).

3.2.7. HLMs reactive metabolite detected at $m / z 460$ (M9). The SAP metabolite detected at $\mathrm{m} / \mathrm{z} 460$ eluted at $32.9 \mathrm{~min}$ (M9). The fragmentation of M9 ion resulted in three DIs detected at $\mathrm{m} / \mathrm{z}$ 320, $m / z$ 141, and $m / z 87$ (Fig. 9). Compared with SAP fragmentation, the DI detected at $m / z 320$ did not show any relevant metabolic pathway in the B substructure. On the other hand, the DI detected at $m / z 141$ revealed oxidative dealkylation of an acetamide group, leading to the generation in the A substructure of an aldehyde intermediate that formed an oxime adduct with $\mathrm{MeONH}_{2}$, matching with the structure of the DI detected at $m / z 87$ (Scheme 10).

\subsection{Bioactivation pathways of SAP}

The presence of M7 and M8 cyano adducts underlined the bioactivation of the piperidine ring (cyclic tertiary amine) during SAP metabolism. Indeed, the hydroxylation metabolic reaction at $\alpha$-carbons linked to the tertiary nitrogen of piperidine ring followed by water loss led to the formation of reactive iminium intermediates that were trapped with cyanide to form the stable cyano adducts M7 and M8. The detection of the M9 oxime confirmed the formation of an aldehyde intermediate. Specifically, the oxidative dealkylation of the acetamide group

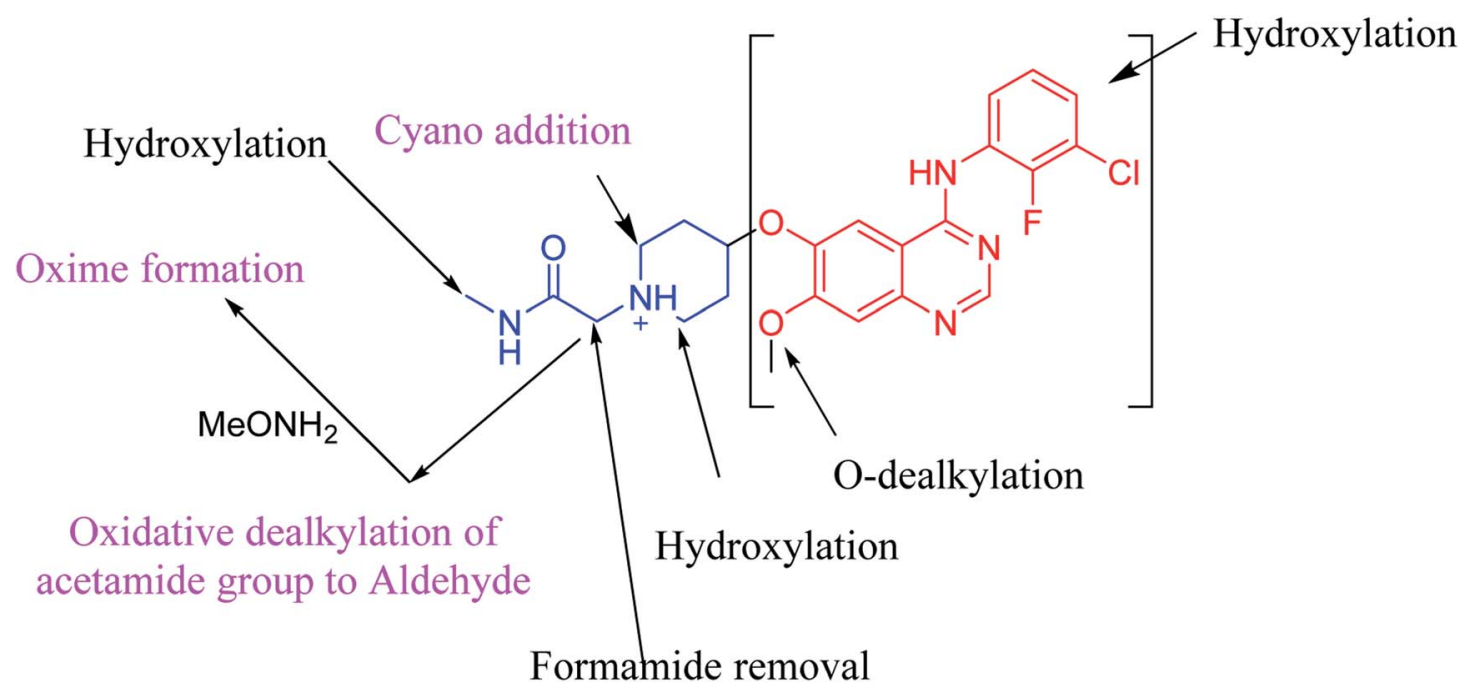

\section{Sapitinib}

Fig. 10 Metabolic and bioactivation pathways of SAP. 
generated an unstable aldehyde intermediate that was trapped by $\mathrm{MeONH}_{2}$, forming the stable oxime M9. Two cyano and one oxime adducts were characterized using LC-MS/MS. Scheme 11 shows the pathways involved in SAP bioactivation during its metabolism.

\section{Conclusion}

We characterized six SAP metabolites using LC-MS/MS in addition to two iminium ions and one aldehyde reactive metabolite. We were able to define two bioactivation pathways for SAP (Fig. 10) from these results (Scheme 11). First, the piperidine-ring carbons were bioactivated during SAP metabolism and captured by cyanide ions. Second, the oxidative dealkylation of the acetamide group led to the formation of an aldehyde that was attacked by $\mathrm{MeONH}_{2}$, generating an oxime adduct. The generation of these reactive intermediates in SAP metabolism might be associated with its reported side effects. This study therefore provides relevant insights for the development of second-generation drugs with improved safety profiles. Building new drugs by blocking SAP-bioactivation center or characterization of isosteric replacements for the attacked hydrogen atoms could indeed lead to a decrease in side effects while keeping SAP activity intact.

\section{Conflicts of interest}

None.

\section{Abbreviations}

$\begin{array}{ll}\text { ACN } & \text { Acetonitrile } \\ \text { DI } & \text { Daughter ion } \\ \text { EGFR } & \text { Epidermal growth factor receptor } \\ \text { ESI } & \text { Electrospray ionization } \\ \text { FI } & \text { Fragment ion } \\ \text { HLMs } & \text { Human liver microsomes } \\ \text { LC-MS/MS } & \text { Liquid chromatography-tandem mass } \\ & \text { spectrometry } \\ \text { KCN } & \text { Potassium cyanide } \\ \text { MeONH } & \text { Methoxyamine } \\ \text { PI } & \text { Product ion } \\ \text { SAP } & \text { Sapitinib } \\ \text { TKI } & \text { Tyrosine kinase inhibitor }\end{array}$

\section{Acknowledgements}

The authors would like to extend their sincere appreciation to the Deanship of Scientific Research at the King Saud University for funding this work through Research Group Project No. RG1437-033.

\section{References}

1 Z. Blanchard, B. T. Paul, B. Craft and W. M. ElShamy, Breast Cancer Res., 2015, 17, 5.
2 D. M. Hickinson, T. Klinowska, G. Speake, J. Vincent, C. Trigwell, J. Anderton, S. Beck, G. Marshall, S. Davenport, R. Callis, E. Mills, K. Grosios, P. Smith, B. Barlaam, R. W. Wilkinson and D. Ogilvie, Clin. Cancer Res., 2010, 16, 1159-1169.

3 P. Ballard, H. C. Swaisland, M. D. Malone, S. Sarda, S. Ghiorghiu and D. Wilbraham, Xenobiotica, 2014, 44, 1083-1098.

4 S. R. Knowles, J. Uetrecht and N. H. Shear, Lancet, 2000, 356, 1587-1591.

5 C. Ju and J. P. Uetrecht, Curr. Drug Metab., 2002, 3, 367-377. 6 S. Ma and M. Zhu, Chem.-Biol. Interact., 2009, 179, 25-37.

7 A. F. Stepan, D. P. Walker, J. Bauman, D. A. Price, T. A. Baillie, A. S. Kalgutkar and M. D. Aleo, Chem. Res. Toxicol., 2011, 24, 1345-1410.

8 A. A. Kadi, M. W. Attwa and H. W. Darwish, RSC Adv., 2018, 8, 1182-1190.

9 A. A. Kadi, S. M. Amer, H. W. Darwish and M. W. Attwa, RSC Adv., 2017, 7, 36279-36287.

10 M. W. Attwa, A. A. Kadi, H. W. Darwish and H. Alrabiah, Clin. Chim. Acta, 2018, 482, 84-94.

11 M. N. Paludetto, F. Puisset, E. Chatelut and C. Arellano, Med. Res. Rev., 2019, 1-48.

12 M. W. Attwa, A. A. Kadi, H. Alrabiah and H. W. Darwish, J. Pharm. Biomed. Anal., 2018, 160, 19-30.

13 M. W. Attwa, A. A. Kadi and A. S. Abdelhameed, RSC Adv., 2018, 8, 38733-38744.

14 M. W. Attwa, A. A. Kadi and A. S. Abdelhameed, J. Pharm. Biomed. Anal., 2019, 164, 659-667.

15 L. P. Mašič, Curr. Drug Metab., 2011, 12, 35-50.

16 S. Ma and R. Subramanian, J. Mass Spectrom., 2006, 41, 1121-1139.

17 A. Tolonen, M. Turpeinen and O. Pelkonen, Drug Discovery Today, 2009, 14, 120-133.

18 H. W. Darwish, A. A. Kadi, M. W. Attwa and H. S. Almutairi, Clin. Chim. Acta, 2018, 480, 180-185.

19 H.-T. Arkenau, J. C. Sachdev, M. M. Mita, R. Dziadziuszko, C.-C. Lin, J. C. Yang, J. R. Infante, S. P. Anthony, M. Voskoboynik, W.-C. Su, J. D. De Castro, R. B. Natale, Z.-Y. Zhang, L. Hughes, D. Bobilev and G. J. Weiss, J. Clin. Oncol., 2015, 33, 8063.

20 A. A. Kadi, R. F. Angawi, M. W. Attwa, H. W. Darwish and A. S. Abdelhameed, J. Chem., 2013, 2013, 9.

21 A. A. Kadi, A. S. Abdelhameed, H. W. Darwish, M. W. Attwa and A. H. Bakheit, Trop. J. Pharm. Res., 2016, 15, 2683-2692.

22 A. A. Kadi, A. S. Abdelhameed, H. W. Darwish, M. W. Attwa and N. S. Al-Shakliah, Biomed. Chromatogr., 2016, 30, 12481255.

23 S. M. Amer, A. A. Kadi, H. W. Darwish and M. W. Attwa, $R S C$ Adv., 2017, 7, 4479-4491.

24 M. W. Attwa, A. A. Kadi, H. Alrabiah and H. W. Darwish, J. Pharm. Biomed. Anal., 2018, 160, 19-30.

25 N. Castagnoli, Jr., J. M. Rimoldi, J. Bloomquist and K. P. Castagnoli, Chem. Res. Toxicol., 1997, 10, 924-940. 